\title{
UN ANÁLISIS DE LAS FORMAS DE TRATO DESDE UN ENFOQUE SOCIOLINGÜÍSTICO
}

\author{
Alina Bestard Revilla \\ Universidad de Oriente (Cuba) \\ abestard@uo.edu.cu
}

Recibido: 21/10/2019 - Aprobado: 16/12/2019

DOI: doi.org/10.17533/udea.lyl.n77a11

\begin{abstract}
Resumen: El estudio reflexionó acerca del movimiento experimentado en el eje poder/solidaridad, que afecta el uso de las formas de tratamiento en una comunidad urbana de Santiago de Cuba, relacionado con las transformaciones socioeconómicas de las últimas décadas en Cuba. Luego de la recolección de datos realizada y de su confrontarse por triangulación de datos tomados de otras zonas santiagueras, fue posible la conformación de un corpus lingüístico. Los resultados indican que el movimiento está vinculado con los conceptos emergentes de poder, relacionados con el estatus socio-económico de los hablantes. Se expondrán los orígenes, usos y significados de tales conceptos.
\end{abstract}

Palabras clave: poder/solidaridad; formas de tratamiento; cortesía verbal.

\section{AN ANALYSIS OF THE FORMS OF TREATMENT FROM A SOCIOLINGUISTIC APPROACH}

\begin{abstract}
The study reflected on the movement experienced in the power/solidarity axis, which affects the use of forms of treatment in an urban community of Santiago de Cuba, related to the socio-economic transformations of recent decades in Cuba. After the collection of data and its comparison by data triangulation taken from other parts of Santiago, it was possible to form a linguistic corpus. The results indicate that the movement is linked to the emerging concepts of power, related to the socioeconomic status of the speakers. The origins, uses and meanings of such concepts will be presented.
\end{abstract}

Key words: power/solidarity; forms of treatment; verbal politeness. 


\section{Introducción}

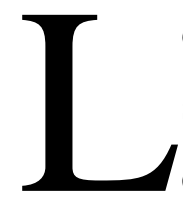

os estudios tradicionales sobre la cortesía se han caracterizado por destacar solamente los valores sociales y meramente formularios inherentes a esta, y han desdeñado su aspecto individual, creativo y estratégico. Por ello, fue preciso enfocar el estudio de la cortesía desde un punto de vista funcional y no tan solo formal. En tal sentido, se ha avanzado en los últimos años con los trabajos de Bravo (2003, 2004), Briz (2004), Sielbold (2008) y Moser (2010), entre otros.

En los últimos veinte años del siglo XX se han destacado, por su enfoque sociológico y funcional en los estudios de la cortesía, los trabajos de Brown y Levinson (1987), que recogieron el modelo más desarrollado e influyente sobre los estudios de la cortesía. La publicación de las teorías de Brown y Levinson (1987) ha incrementado de manera considerable las investigaciones sobre la cortesía verbal dentro del paradigma de la pragmática. El creciente desacuerdo con la pretensión de validez universal de estas teorías ha conducido a una serie de estudios sobre la cortesía verbal que han puesto como relieve características culturales específicas. La investigación de la cortesía verbal contribuye decisivamente a la comprensión de la acción verbal en general y, además de ello, explica muchos de los fenómenos emergentes en situaciones de comunicación interculturales determinados como tales en el sentido más amplio del término-, como los que se generan en encuentros de diferentes subgrupos sociales y el enfrentamiento de sus reglas de cortesía respectivas — por ejemplo, en el habla juvenil—. En este estudio se analizará el uso de las formas de tratamiento como manifestación de la cortesía verbal en los diferentes niveles del habla, que abarcan desde las formas de tratamiento hasta la organización discursiva, expresada en convenciones, rituales y estrategias (Kerbrat-Orecchioni, 2004; Portolés, 2004; Rebollo 2006; Schrader-Knffki, 2006; Koch, 2008; Siebold, 2008; Fetzer, 2011; Schrott, 2017), Bestard, (2017, 2019a, 2019b, 2019c). Si bien han aumentado los estudios sobre la cortesía en español, todavía se observan algunas insuficiencias en las investigaciones de este tipo, tanto más si se considera la extensión del grupo y la diversidad de las diferentes culturas hispanohablantes (Cordisco, 2003; Barrera, 2013; Amati, Isella, \& Lois, 2014). En general, la idea de todos los autores mencionados anteriormente se centra en dos aspectos esenciales: Caracterizar los sistemas y estrategias de cortesía de otras culturas y diferenciar las culturas en lo que a patrones de relación y cortesía se refiere. 
En tal sentido, este trabajo presentará una indagación sociolingüística sobre el cambio en el comportamiento de las formas de tratamiento - como parte integrante de la cortesía verbal- en las relaciones interpersonales dentro de un área urbana del casco histórico de Santiago de Cuba, como consecuencia de las modificaciones socioeconómicas producidas en el país a partir del derrumbe del campo socialista en Europa. (Martín, Perera Pérez \& Díaz, 1996), Causse (1999) El estudio, además, hizo posible observar las características que distinguen al santiaguero de otras provincias cubanas, así como aquellas que lo acercan a los países de la comunidad lingüística caribeña con los cuales comparten muchos nexos histórico-culturales y que se entrelazan en un pasado común. (Cuba, 2000; Murillo, 2003; Muñoz, 2005; Bestard, 2006).

\section{Marco teórico-referencial}

\subsection{Generalidades acerca del vínculo entre lengua-sociedad-cultura}

La lengua como elemento transmisor de comunicación del hombre refleja las transformaciones económicas, políticas, sociales, culturales y científicas que se producen en la realidad objetiva (Causse, 2000; Barrera, 2013; Amati; 2014), Dentro de ella, el nivel léxico es uno de los niveles más dinámicos y que con mayor rapidez plasma estos cambios. Así, se pueden tomar como ejemplo todas aquellas denominaciones nuevas, que surgen como una necesidad social, las cuales identifican los inventos tecnológicos modernos y el impacto que causan en la vida de los individuos. No quiere esto decir que ante los cambios se cree una lengua nueva, como lo planteado por el marrismo ${ }^{1}$, pues esto no permitiría la identificación cultural como comunidad social integral. De tal manera, el estudio que se hizo sobre las formas de tratamiento y la cortesía se inserta en esta problemática, la relación lengua-sociedad-cultura, donde se aprecia cómo, a consecuencia de las transformaciones socioeconómicas ocurridas en el contexto cubano santiaguero actual, se modifican estas formas léxicas que se estudiarán aquí y que resultan tan importantes en las relaciones interpersonales de los individuos (Bravo, 2004). Estos cambios han influido grandemente en

1. El marrismo fue un movimiento lingüístico auspiciado por el georgiano Nicolái Yákolevich Marr (1864-1934). Concebido para contrarrestar los supuestos excesos del comparatismo y, en especial, del idealismo burgués. Consideró que los miembros de una misma clase social de distintas culturas y nacionalidades pueden comunicarse mejor que los miembros de clases distintas dentro de una misma nacionalidad. 
el contexto social cubano a partir de los años 90 del siglo XX, provocando contradicciones entre sus miembros, por lo que, como parte de esta realidad, la lengua y, en especial, el nivel léxico, han experimentado modificaciones. El español hablado en Cuba ha evidenciado de manera muy dinámica estas transformaciones, presentes en todas las esferas de la vida del cubano actual, por ejemplo, bicitaxi (híbrido de bicicleta con asientos traseros que se alquila como un taxi), maceta (persona adinerada), camello (transporte colectivo urbano), machacante (cobrador de los transportes colectivos), candonguero (vendedor ambulante), onatista (particular que vende artículos sin vínculos con el gobierno), entre otras. Muchas de ellas redimensionan su significado y adquieren nuevas acepciones, como en el caso de camello (animal) o maceta (recipiente para sembrar flores o plantas ornamentales).

En la actualidad, es un aspecto evidente en los estudios del lenguaje la relación lenguasociedad, pues su vínculo resulta fundamental y universal para la comunicación, especialmente de la divulgación del progreso social y de los logros de la revolución científico-técnica a toda la humanidad, sin devaluar el significado de la informática computarizada moderna. Es por ello una tarea insoslayable de los lingüistas y demás estudiosos del lenguaje concentrar sus esfuerzos en el estudio y desarrollo de la misma, así como lograr la solución de numerosos problemas que aún subsisten en el campo, pues es necesario tener muy clara la relación lengua-sociedad. De ahí la importancia que Romaine (1996) concede a estas interacciones cuando afirmó que «hay cruciales conexiones entre las cuestiones sociopolíticas a gran escala investigadas por la sociología del lenguaje, y las formas, usos lingüísticos a pequeñas escalas, que constituyen el objetivo de la sociolingüística» (Romaine, 1996, p. 13). La autora aseguró, además, que los estudios sociales deben reservar un lugar al lenguaje, así como el estudio del lenguaje debe tener en cuenta a la sociedad.

Sin embargo, la misma autora argumentó que la lengua no es simplemente el reflejo de una realidad objetiva modelada a su manera, sino que contribuye a dar sentido al mundo. Al clasificar la realidad se le da una estructura y la lengua permite construirla. En otras palabras, de la interacción humana con su entorno y el acuerdo consciente de la sociedad surgen las denominaciones y conceptos que lo clasifican (Romaine, 1996, p. 42).

La misma autora expresó también que ninguna lengua puede ostentar el privilegio «de ver el mundo como es en realidad». El mundo no es como es, sino como se hace a través del lenguaje (Romaine, 1996). A partir de esto, se deduce que las correlaciones entre estructura 
lingüística y estructura social no explican nada, a no ser que se enmarquen en las conductas humanas.

Como parte de lo que genéricamente se ha llamado formas de tratamiento, se tiene en cuenta a la hora de hablar con una segunda persona, con expresiones marcadoras de intimidad y condescendencia, en alternancia con las formas de distancia social y deferencia, tanto en el nivel gramatical, léxico y discursivo.

\subsection{Las formas de trato y el sistema pronominal de tratamiento en español: $\mathrm{Su}$ variación en Cuba}

Las denominadas formas de tratamiento aluden a aquellas fórmulas de cortesía (nombres, hipocorísticos, apodos y pronombres personales de segunda persona) que sirven para dirigirse a alguien en la comunicación, tanto oral como escrita ${ }^{2}$. Estos poseen una fuerte carga semántica que varía según cada sociedad y cada época. Por ello, no es posible estudiarlas sin un conocimiento previo del marco histórico, social, económico, político y cultural en el que surgieron, pues se trata de una parte de la lengua estrechamente ligada al tipo de organización social propio de cada comunidad de habla y, por lo tanto, dependiente de las modificaciones que impone el desarrollo histórico y social, como ya se dijo anteriormente. De su particular tendencia a la innovación ha dado cuenta tradicionalmente la gramática histórica, la cual representa uno de los temas clásicos abordados por la filología hispánica (Molina, 2002).

Por otro lado, el sistema pronominal de tratamiento constituye, por su amplia variación regional, uno de los aspectos de la morfosintaxis española, debido a su variedad de formas y a la complejidad de la combinación de este sistema pronominal con las formas verbales. Actualmente, existen cuatro sistemas pronominales de tratamiento en el mundo hispánico (Gramática descriptiva de la lengua española, Tomo I, 2000, pp. 1401-1404). Según esta clasificación, en Cuba se emplea el sistema pronominal III b, que básicamente, emplea tú para el trato de mayor confianza y afectividad, y usted para el distanciamiento y respeto.

Dentro del nivel léxico, las formas de tratamiento han sufrido ciertos cambios. En algunos casos han surgido nuevas formas, mientras que otras han modificado su significación al añadir otros matices conceptuales que responden a la necesidad de designar

2. Resulta imposible tener una visión de conjunto acerca de los usos del sistema de tratamiento en español sin vincular las fórmulas de tratamiento pronominales con las fórmulas de tratamiento nominales, por la relación tan estrecha que poseen (Gramática descriptiva de la lengua española, Tomo I, 2000, p. 1418). 
los fenómenos sociales surgidos, como, por ejemplo, empleos (vinculados al turismo o a la esfera económica no estatal), actividades sociales (salidas ilegales del país), conductas sociales (prostitución, drogas, juegos de azar), etc. Sin embargo, hay rasgos vinculados con tales términos que se mantienen como características inherentes a las formas de trato del santiaguero; entre ellas se pueden destacar la afectividad, que refleja la hospitalidad, sencillez y solidaridad propias del cubano. Dicho rasgo ha sido apuntado en investigaciones anteriores (Callejas, 1983; Bermúdez, 2005; Muñoz, 2005; Reyes, 2005).

\subsection{Caracterización sociocultural de la ciudad de Santiago de Cuba: Transformaciones económicas, políticas, sociales y culturales a partir de los años 90 del siglo $\mathrm{XX}$}

La ciudad de Santiago de Cuba, segunda en importancia de Cuba, también ha pasado por transformaciones en su vida cotidiana durante los últimos años; al igual que el resto del país, ha trabajado duramente para solucionar los conflictos que aquejan a su comunidad. La zona de estudio seleccionada para esta indagación fue el casco histórico de la ciudad mencionada, por la presencia de personas procedentes de diversos orígenes y el contacto diario que establecen con los residentes permanentes de la zona. Dichos aspectos permitieron obtener una mayor variedad y riqueza en las formas de tratamiento, encontradas en el espacio temporal que cubre el trabajo — desde finales del siglo pasado hasta 2005-.

La población vive generalmente en la parte alta de la arteria comercial y cultural del área estudiada. Las viviendas son principalmente de mampostería y algunas conservan el frente de adobe, con techos de tejas francesas y españolas; otras residencias son de madera y de placa, construidas entre los siglos XIX y XX. También existe en la zona un número considerable de cuarterías y albergues. Uno de los problemas más comunes de las viviendas en esta zona es su deterioro estructural. Los servicios públicos y de saneamiento están plenamente garantizados. El valor cultural, económico y socio-político que posee esta zona es considerable y, de hecho, es el centro de intercambio social más fuerte de la ciudad, por ser un área netamente comercial. Buena parte de los acontecimientos artísticos, culturales, sociales, económicos, religiosos y políticos ocurren en este entorno, donde se encuentran la mayor cantidad de instituciones dedicadas a dichas actividades.

El entorno socio-cultural del casco histórico santiaguero hace que tenga un sello distintivo frente al resto de las ciudades cubanas, lo que contribuye al permanente flujo de personas y de visitantes hacia esta área, convirtiendo a la ciudad santiaguera en uno de los 
polos turísticos más importantes de Cuba y, al mismo tiempo, en un espacio ideal para el estudio efectuado sobre las formas de tratamiento surgidas en la última década del siglo XX.

Como prueba de ello se constituye la realidad actual de la ciudad, la cual genera problemas de diversa índole a sus habitantes, los cuales han provocado contradicciones entre ellos, que se reflejan en su habla, especialmente en su comportamiento lingüístico y en su cortesía verbal. Cabe recordar que, a partir de la década de los 90 se inició una serie de transformaciones económicas, políticas, sociales y culturales en Cuba, debido al derrumbe del antiguo campo socialista con el cual el país sostenía la mayoría de sus relaciones comerciales. Dichas transformaciones incidieron considerablemente en la vida socioeconómica y cultural del cubano, modificando el léxico y, dentro de él, las formas de tratamiento que respondieron a la necesidad del hablante de expresarlas.

Problemas que hasta ese momento habían sido superados por el país comenzaron a ocupar lugares determinantes en la vida cotidiana del cubano, como la reaparición de la prostitución, la falta de combustible, que generó dificultades con el transporte, la carencia de artículos de primera necesidad, el déficit de productos alimenticios y medicamentos, entre otros. Ante esta situación adversa, fue necesario tomar medidas que la contrarrestaran, las cuales modificaron la vida cotidiana de los cubanos, como la promoción del uso masivo de medios alternativos de transporte (bicicletas, camellos, taxi-bus, bici-taxis), la aparición de la empresa privada, el trabajo independiente, la creación de nuevos puestos de trabajo, las salidas ilegales masivas del país, los acuerdos migratorios con los Estados Unidos, la apertura al capital extranjero con la formación de empresas mixtas, la despenalización de la tenencia de divisas, la dolarización de los servicios públicos, la desprofesionalización de la mano de obra y la apertura del mercado agropecuario regido por la ley de la oferta y la demanda, así como el desarrollo del turismo como industria en ascenso, con sus posteriores secuelas negativas, tales como el aumento de la prostitución, la drogadicción y el alcoholismo entre la población (Martín, 1996, p. 95).

La aparición de estos cambios socioculturales repercutió en el habla del cubano, especialmente en los rituales de cortesía y particularmente, en las formas de tratamiento, que expresaron estas transformaciones sociales. La necesidad de nombrar esas nuevas realidades sociales fruto de ese periodo histórico hizo posible el surgimiento de estas variaciones en el uso de las formas de tratamiento, tanto nominal como pronominal.

\subsection{Metodología y métodos empleados}


El universo investigativo escogido engloba a toda la población residente del casco histórico. Sin embargo, la atención se dirigió particularmente hacia aquel sector de la población que hubiese residido en la zona por más de diez años, o que llevara trabajando allí durante ese mismo periodo de tiempo. De acuerdo con ello, la muestra poblacional seleccionada quedó dividida en tres subpoblaciones, clasificadas de la siguiente manera:

—Residentes por más de 10 años en la zona

— Trabajadores por más de 10 años de la zona

-Personal flotante ${ }^{3}$ de la zona

Para la muestra se tuvieron en cuenta algunos de los criterios de López Morales (1994, p. 52), referidos a los estudios de actuación linguística — sobre los que se realizaron los análisis de competencia-y también otros criterios (Goetz \& Le Compte, 2002; Rodríguez Gómez et al., 2002). Estos señalaron que, como parte de la estrategia de una investigación cualitativa para seleccionar informantes, es necesario, en primer lugar, localizar grupos y escenarios que hagan posible la selección de ciertos elementos considerados relevantes en las primeras fases de la investigación; y en segundo lugar, seleccionar y comparar casos para la comprobación de implicaciones teóricas (Rodríguez Gómez et al., 2002, pp. 98-103). Las reflexiones acerca de las estrategias planteadas por estos autores permitieron decidir qué datos se debían recoger, dónde encontrarlos y qué tipo de variables independientes debían poseer los sujetos que ofrecerían las informaciones relevantes acerca de los cambios para la investigación planteada. Las variables independientes determinadas para esta investigación fueron:

—Edad: Fueron considerados tres grupos etarios que abarcan los siguientes rangos: 1825 años (I), 26-50 años (II) y de 51 años en adelante (III).

- Sexo: Por tener en cuenta los diversos papeles que asumen los sujetos de uno y otro sexo (femenino y masculino) en la comunidad de habla en su diferenciación social y etaria.

-Nivel de escolaridad: Aporta el nivel sociocultural de los hablantes, que influye en la selección del empleo estándar ${ }^{4}$ de la lengua y el comportamiento sociolingüístico del

3. Como personal flotante se clasifica un grupo considerable de personas que acuden diariamente al casco histórico por diferentes motivos (políticos, administrativos, económicos, culturales, religiosos, educativos, recreativos, etc.). Estas personas pertenecen a las diferentes barriadas de la ciudad, e incluso otros municipios y provincias del país, así como también extranjeros. Su número es variable, pero oscila alrededor de las diez mil personas. Estos datos fueron obtenidos en una entrevista realizada el 23 de mayo de 2005 a la funcionaria Yolanda Fong, del Depatamento Ideológico del Comité Provincial del Partido Comunista de Cuba, en la provincia de Santiago de Cuba. 
hablante. Se definieron como primario $(\mathrm{P})$, secundario $(\mathrm{S})$, medio-superior $(\mathrm{M}-\mathrm{S})$ y universitario (U).

-Profesión: Fueron consideradas especialmente aquellas en las que hay un trato directo con el público (dependientes, recepcionistas, cajeros, porteros, gastronómicos, directores, administradores, gerentes, profesores, etc.). Se asume que la profesión del hablante determina, en gran medida, la posición que este asume y la que otorga al interlocutor en la conversación.

Como variable lingüística dependiente fueron analizadas las formas de tratamiento nominal y pronominal.

La selección de los informantes fue intencional - 18 en total-, atendiendo a los estratos que se precisaba representar y al requisito mencionado con anterioridad: su permanencia como residente o trabajador de la zona por diez años o más, además ser santiagueros.

Dentro de los temas que se abordaron en los cuestionarios se encuentra los siguientes: las profesiones y oficios; el transporte, las actitudes, comportamientos y conductas sociales; las relaciones humanas y los valores ético-morales; las costumbres y las modas, entre otros. Se tuvieron en cuenta, específicamente, aquellos aspectos vinculados con las transformaciones ocurridas en la vida cotidiana del cubano a partir del derrumbe del campo socialista, que han incidido en la modificación de las formas de tratamiento. Se hicieron notas de campo pormenorizadas de las circunstancias y lugares donde se recogió la información, tomándose las expresiones más valiosas para citarlas como testimonio de las realidades observadas. Estas notas sirvieron, además, para reorientar la observación y la propia investigación.

Con el fin de lograr un mayor acercamiento a la realidad objeto de estudio, se aplicó un cuestionario de tipo onomasiológico, para el cual se contó con el apoyo del libro El habla popular cubana de hoy (1985), de Argelio Santiesteban, con una temática similar a la planteada. Además, se consideró también el modelo metodológico de encuestas seguido por Murillo (2005, p. 115), quien para el análisis de la cortesía lingüística en Costa Rica tuvo en cuenta los hábitos y apreciaciones sociales de los costarricenses. A tales efectos, se siguió el siguiente plan:

a) Formas pronominales de tratamiento (tú/usted)

4. Se asume como lengua estándar el concepto planteado por Alvar (1996), que la refiere como el resultado de un consenso basado en los usos literarios, identificándola técnicamente con la langue de Ferdinand de Saussure, que es la existente en todas partes y aceptada por todos los hablantes $-\mathrm{y}$ no solo por los escribientes - , pero que nadie utiliza. Sin embargo, esta lengua cumple la función de mantener la unidad del sistema. Es el referente válido en un momento dado en la inmensa superficie en la que el español se habla, aunque la realización de ese sistema abstracto puede tener pluralidad de actualizaciones. 
- Situaciones en que se emplean

- Personas a las que se les dirigen

-Factores que se toman en cuenta en la selección de una forma pronominal de tratamiento

b) Formas nominales de tratamiento (nombres, apodos e hipocorísticos)

-Nuevas formas nominales de tratamiento en las relaciones sociales

-Personas a quienes se les dirigen

c) Actitudes hacia las formas de tratamiento en la comunidad

-Negativas:

-Fenómeno generacional

-Fenómeno educativo

—Diferencias socio-económicas

-Otras

-Positivas:

—Aumento de la solidaridad y del compañerismo

El objetivo de esta encuesta estuvo dirigido a compilar el mayor número de formas nominales de tratamiento surgidas en esta etapa, a comprobar los cambios operados en el uso del sistema pronominal de tratamiento y relacionar la influencia que las variables independientes ejercen en la selección de una forma de trato. Además, se analizó en qué medida las transformaciones socioeconómicas ocurridas en el país han incidido en el uso, frecuencia y significado actual de las formas de tratamiento en Santiago de Cuba.

Los cuestionarios se elaboraron con preguntas sencillas y abiertas, de manera tal que el informante respondiera de forma libre y desprejuiciada a las preguntas que se le hacían. Las temáticas sugeridas resultaron ser de interés para los entrevistados y primó entre ellos la intención de cooperar con la investigación. En la formulación de los cuestionarios se evitó introducir la denominación o forma de tratamiento esperada, a través de algún lexema derivativo. En algunos casos, se hicieron preguntas de profundización - a modo de entrevista - para obtener información más completa sobre lo que se indagaba.

Se procedió de esa manera cuando el encuestado aseguraba no conocer ninguna respuesta o sólo una de las previstas, como, por ejemplo:

— ¿Cómo se le dice al que cobra en los camiones o camionetas de pasaje?

-Machacante.

— ¿Qué nombre(s) recibe el extranjero en Cuba?

-Pepe, pitirre, yuma... 
Esto quiere decir que si se contaba con una serie de posibles respuestas para una misma noción y el informante utilizaba exclusivamente una de ellas, se acudía a la indagación más profunda para obtenerlas.

Los cuestionarios tienen la ventaja de permitir la recogida de una cantidad considerable de información, pero alejan al investigador de la espontaneidad que permite el registro informal. Por tal motivo, se aplicó también la técnica de la observación participante en los lugares públicos seleccionados de la zona estudiada, ya mencionados anteriormente. Se escogieron instituciones que prestan servicios públicos a la población en moneda nacional y en divisas, en donde la afluencia de personas es notable, con la finalidad de observar regularidades y comportamientos que permitieran comprender, explicar e interpretar el comportamiento individual y social de los sujetos implicados.

\section{Resultados y discusión}

Además de las formas nominales de tratamiento tradicionales que designan el parentesco, el físico de la persona o la semejanza con animales, se encontraron otras que designan aspectos de la vida social actual de la comunidad, como jinetero,-a (prostituta, chulo), amarillo,-a (trabajador del transporte público), balsero,-a (emigrante cubano que sale ilegalmente del país por mar), maceta (persona adinerada), machacante (cobrador del transporte urbano) y gerente (cargo público en los hoteles, persona adinerada). Junto a ellas se comprobó la variación en las acepciones de otras, tales como millonario,-a (persona contagiada con enfermedades de transmisión sexual), cuadro (dirigente, jefe), bárbaro,-a (persona $\mathrm{u}$ objeto con cualidades apreciables) y luchador,-a (prostituta), las cuales han añadido nuevos conceptos y han sido adaptados a la realidad designada. En el caso de millonario,-a, se nota cómo después del triunfo de la Revolución cubana se empezó a llamar con ese adjetivo al machetero destacado en su puesto de trabajo por cortar una gran cantidad de arrobas de caña de azúcar. En la actualidad, se designa de ese modo a la persona que por tener una actitud sexual promiscua y desprotegida debe tomar muchas medicinas para el tratamiento de su enfermedad.

Se encuentra además el tratamiento de señor,-a, que había experimentado una disminución en la frecuencia de uso en la década de los 60 en Cuba, siendo sustituida por la forma de tratamiento compañero,-a, como manifestación de las relaciones amistosas (Cuba, 1996). Actualmente, a consecuencia de la masificación del turismo extranjero en el país, 
nuevamente se ha visto incrementado el empleo de la forma señor,-a, como un tratamiento de respeto que se exige para los turistas en hoteles, tiendas, oficinas, entre otros lugares. Se ha hecho extensivo también a otras personas que, ante la dolarización de la economía y la llegada de divisas al país, han adquirido un estatus socioeconómico diferente al de otras personas con un menor nivel de ingresos. Caso similar ocurrió con el tratamiento de maceta, surgido de la Operación Maceta, un operativo policial llevado a cabo en el país en 1993, consistente en la confiscación de mercaderías ilegales y la captura de contrabandistas.

Por su parte, los tratamientos de pepe, pitirre y yuma designan también a los turistas extranjeros de cualquier nacionalidad. En el caso de yuma se refiere especialmente a los ciudadanos cubano-americanos que residen en Estados Unidos y visitan Cuba. La condición que iguala en el tratamiento, tanto al extranjero como al residente, es la tenencia de divisas y un nivel de vida socioeconómico diferente al de los connacionales.

Hay que destacar que estas formas de tratamiento son voces clasificadas como nombres, en su categoría funcional sustantiva. Además, se observó que, en el uso, estas formas pueden aparecer en función apelativa o referencial. Por lo general, algunas de las formas que se emplean de manera referencial poseen un matiz ofensivo, lo que explica su uso no apelativo o directo, que violaría las normas de cortesía entre los hablantes. Los hablantes emplean, pues, las formas de tratamiento referencialmente para no apelar directamente a la conducta o actividad social que desempeña la persona. El uso referencial demuestra que los hablantes conocen el significado del término, pero no admiten usarlo apelativamente. Estos términos, aunque aparecen en función sustantiva, son calificativos, es decir, adjetivos en función sustantiva que nombran o designan, como obstinado (muy pobre), asfixiado (muy pobre), homosexual o jinetera. La función principal de las formas de trato es nombrar, independientemente de que se esté asignando un calificativo a la persona que se nombra o coincida con la opinión del interlocutor. En formas de tratamiento como jinetera, empleadas mayormente de manera referencial, se observó el uso apelativo en los casos de ofensas directas hacia la segunda persona o atenuada con el diminutivo, para brindar un matiz de cariño o afecto, por ejemplo, cuando una madre se dirige a su niña pequeña para decirle «pero si es una jineterita», como un halago.

\subsection{Procedimientos de la formación de la estructura léxico-formal de las formas de trato en Cuba}


Con respecto a su estructura léxico-formal, estos términos se han formado de acuerdo con los siguientes procedimientos:

- Trasgresión semántico-gramatical de una palabra, ej., amarillo y mula. En ambas voces se mantiene el género del lema, por lo que es el artículo precedente el que determina el género de la persona.

-Ampliación del significado de palabras que ya existen en el idioma español, pero que en el período estudiado aparecen con otro significado, ej., maceta.

-Neologismos:

-Por composición normal, ej., cuentapropista, bicitaxista.

-Por derivación, ej., onatista.

-Por metáfora, ej., jinetera.

-Préstamos del inglés (man), italiano (amici) y el francés (monsieur).

-Deslexicalización de formas de tratamiento que han perdido su carga peyorativa, ej., hijo de puta, yegua, maricón.

- Sustantivación de adjetivos en función de nombrar, ej., un asfixiado, el mariquita, el aberrado.

-Empleo del diminutivo como atenuante de la carga ofensiva de algunas formas de tratamiento usadas de manera directa, ej., jineterita, viejito, putica.

\subsection{Descripción y análisis del comportamiento de las formas de trato estudiadas}

Se encontraron formas vinculadas al turismo, como gerente, subgerente, ama de llaves, mucama, cvp (cuerpo de vigilancia y protección), que designan a los nuevos puestos de trabajo creados luego de la apertura económica.

Hay que señalar nuevamente, como consecuencias de los cambios que sufrió Cuba en los años 90, la aparición de problemáticas sociales como el aumento de la prostitución, la drogadicción y el alcoholismo entre la población. El lenguaje, fiel reflejo de esta realidad, la expresa a través de formas de tratamiento, como jinetera (persona que ofrece sus servicios sexuales a extranjeros a cambio de dinero) o trabajadora social (eufemismo que designa a las trabajadoras sexuales), forma que en su sentido original hace referencia a las personas dedicadas a las labores comunitarias.

Por otro lado, para los alcohólicos existen un sinnúmero de formas nominales de tratamiento, que aluden al estado de embriaguez o a la calidad de la bebida, p. ej., tribuna 
abierta (hablador), balín (al que camina rápido), dragonauta, aliento e’tigre o de león (al que expele el aliento propio de los bebedores), walfarina, colaíto, alcolifai, químico (el que bebe ron de baja calidad).

Con relación al tratamiento pronominal propiamente dicho, la norma en Cuba es el uso de tú/usted/ustedes, a excepción de una pequeña parte de la provincia de Camagüey, donde aún se preservan algunos vestigios de voseo (Blanco, 1980). Según Brown y Gilman (1960), estos usos estarían relacionados con la oposición poder/solidaridad, la cual determina que un hablante escoja una u otra forma pronominal de tratamiento. Al principio de la Revolución cubana, las relaciones sociales camaraderiles establecidas en el país incidieron en un aumento del tuteo en las relaciones cotidianas, laborales, familiares y sociales de los cubanos, sin perderse, claramente, el uso del usted/ustedes como tratamiento de respeto hacia desconocidos, personas mayores de edad o con cargos profesionales de importancia (Cathcart, 1981; Cuba, 1996; Bestard, 2014, 2015, 2016).

Se apreció un aumento del tuteo hacia personas que anteriormente, a razón de su edad, eran tratadas de usted. De acuerdo con el nuevo concepto de poder presente en la mente del hablante, en relación con las nuevas condiciones socio-históricas de Cuba, se observaron variaciones en este uso como parte del «conocimiento tácito» que el hablante posee sobre estos cambios y que se manifiesta a través de la preferencia hacia el uso de una forma de trato determinada. Los informantes reconocieron que el empleo de usted debe reservarse no solo para los adultos mayores, sino también a otras personas que, por el nivel de su cargo, su condición de extranjeros, poseer divisas o considerárseles adineradas, debían recibir un tratamiento de distancia y de respeto.

\subsection{El eje poder/solidaridad en las formas de trato y el sistema pronominal}

Muchas veces esta selección se aleja de la norma establecida para determinadas circunstancias comunicativas, pues las apreciaciones del hablante se afinan tan pronto como entran en juego los ejes de poder y solidaridad en relación con el interlocutor, lo cual demuestra su competencia comunicativa. El uso pronominal observado estuvo determinado por la edad, el sexo, la profesión, el nivel de instrucción y el tipo de interlocutor.

Se acopiaron un total de 1056 formas de tratamiento relacionadas con sus variaciones en el uso, a partir de los cambios socioeconómicos, políticos y culturales ocurridos en Cuba durante los últimos 30 años. El comportamiento de las variables sociolingüísticas corrobora 
estos resultados. En términos del sexo, los hombres resultaron ser los más innovadores en el uso de las formas de trato estudiadas, pues puede afirmarse que suelen usar mucho más su ingenio para crearlas y también mostraron tener un comportamiento más dominante (Del Rosal, 2000). Los hombres son, de este modo, los más productivos en el uso de las formas de tratamiento, ya que aportaron un total de 612. En cuanto a la edad, el segundo grupo etario, de 26 a 50 años fue el más productivo, con un total de 302. En cuanto al nivel de escolaridad, el correspondiente al técnico-medio preuniversitario reportó los niveles más altos de uso, con un total de 456. Por último, puede afirmarse que la profesión demostró ser decisiva en cuanto a la selección de una forma de trato por un hablante, porque en la realidad objetiva estudiada la variable de la profesión tiene una estrecha conexión con el estatus socioeconómico del hablante y de su interlocutor y es, por consiguiente, la que sitúa a los participantes de la conversación en una posición de mayor o menor poder.

Debe aclararse que en la sociedad cubana la cercanía, exceso de confianza o igualación social entre generaciones diferentes puede ser interpretada como inapropiada. Generalmente, el tuteo se presenta entre las generaciones más jóvenes como mecanismo de identidad grupal.

En el caso de los rituales de cortesía verbal y las formas de tratamiento, la elección de una forma determinada en situaciones comunicativas diversas remite a las normas linguísticas, al contexto social, al nivel cultural y a los estados anímicos y psíquicos de los hablantes. Estos aspectos imbrican los estudios actuales de la sociolingüística con otras ramas de la ciencia como la psicología, la sociología y la etnología.

El comportamiento lingüístico de un individuo es, al mismo tiempo, un comportamiento de tipo social, pues la selección de un signo lingüístico no es enteramente libre, sino que está sociológicamente condicionada.

Junto a estos factores hay otras afectaciones sociales que se ponen de manifiesto a través del lenguaje, como la violencia mediante el gesto o la palabra, el exceso de familiaridad, el silencio, la indiferencia ante situaciones desagradables, las vociferaciones, las obscenidades, etc., indican que aunque en Cuba se ha dado un proceso de recuperación económica (iniciada en 1996) con un redimensionamiento del sistema socio-económico, aún hay elementos, valores y conductas que se han perdido, y esto se pudo comprobar en este estudio sociolingüístico. Es preciso encauzarse hacia el cumplimiento de las prioridades sociales y la lengua es una vía idónea para ello; puede ayudar a valorizar en lugar de maltratar a las 
personas, así como a recuperar los valores perdidos, estimulando relaciones de respeto, de tolerancia y de convivencia.

\section{Conclusiones}

El estudio de las formas de tratamiento, como parte de la teoría sobre la cortesía verbal, ha permitido describir y analizar sus variaciones lingüísticas, en relación con los cambios socioeconómicos experimentados en Cuba luego del derrumbe del campo socialista mundial, al demostrar el vínculo existente entre la realidad social y la lengua. Las transformaciones a escala social significaron también transformaciones en el orden económico, político y social en cuanto a los sistemas de valores, percepciones, representaciones, ideales, conductas y necesidades de los grupos humanos e individuos particulares inmersos en dicha situación de cambio se refiere, las cuales fueron observadas en la zona histórica de Santiago de Cuba a partir del cambio producido en la dicotomía poder/solidaridad.

Con los resultados alcanzados a través de la descripción, interpretación y explicación del empleo de las formas de tratamiento en el casco histórico de Santiago de Cuba, se cumplieron los objetivos propuestos, al poder precisar las transformaciones que el paradigma de uso del sistema de tratamiento ha sufrido, a partir de las características específicas de la imagen social del hablante, los papeles de los interactuantes en el coloquio y, sobre todo, la incidencia de los rasgos socioculturales particulares del área sujeta a estudio, bajo el supuesto de que estas variables sociales son particulares de cada comunidad. Acercarse a la modalidad del español hablado en Cuba, desde esta perspectiva, posibilitó comprender parte de la identidad cubana manifestada en los comportamientos observados.

El análisis léxico-pragmático de las formas de tratamiento encontradas en el espacio geográfico elegido se concretó en una serie de términos que dan cuenta de los comportamientos humanos, especialmente los prohibidos y restringidos, así como de otras realidades surgidas en una etapa de gran significación para la historia y cultura cubanas, por lo que esta investigación contribuye a enriquecer y salvaguardar en el tiempo los estudios léxico-semánticos, sincrónicos y diacrónicos del español cubano.

\section{Referencias bibliográficas}


1. Amati , M. \& Lois, I. (2014). Comunicación, cultura y conflicto. Ciudad Autónoma de Buenos Aires: Departamento de Publicaciones de la Facultad de Derecho y Ciencias Sociales de la Universidad de Buenos Aires. Ciencias de la Comunicación.

2. Barrera, R. (2013). El concepto de la Cultura en definiciones, debates y usos sociales. Revista de Claseshistoria, 2, ISSN-e 1989-4988.

3. Alvar, M. (1996). Manual de dialectología hispánica. El español de España. Barcelona: Ariel.

4. Bermúdez, S. \& García, E. (2005). Las formas de tratamiento y los calificativos populares en el habla de los jóvenes, en Actas de la IV Conferencia Internacional de Lingüística, 21-25 de noviembre. Instituto de Literatura y Lingüística. La Habana.

5. Bestard, A. (2006). Las formas de tratamiento en la competencia comunicativa de hablantes santiagueros, en Actas Conferencia Internacional Educación, Cultura y Sociedad en Iberoamérica. Matanzas.

6. Bestard, A. (2014). La dicotomía poder/solidaridad en el uso del sistema pronominal y nominal de tratamiento de hablantes santiagueros EFDeportes.com, Revista Digital. Buenos Aires, 18 (188). Recuperado de https://www.efdeportes.com/efd188/la-dicotomia-podersolidaridad-de-hablantes.htm

7. Bestard, A. (2015). El insulto y la (des)cortesía verbal en el espectáculo deportivo santiaguero. Actas del XIV Simposio Internacional de Comunicación Social, 19-23 de enero. Santiago de Cuba. ISBN 978-959-7174-29-5.

8. Bestard, A. (2016). Perspectiva sociolingüística de la cortesía verbal santiaguera. Revista Santiago, 137, Universidad de Oriente. ISBN 978-9594-2-7179-5.

9. Bestard, A. (2017). La violencia verbal en el trato hacia las mujeres como fenómeno sociocultural en Santiago de Cuba. En X Taller Internacional Mujeres del siglo XXI. ISBN: 978-959-7241-16-4.

10. Bestard, A. (2019). El estudio de la comunicación estratégica en espacios laborales públicos de Santiago de Cuba: una vía para el mejoramiento del trabajo administrativo y de dirección. En XIV Simposio Internacional de Comunicación Social. ISBN 957-344-233-67-1. 11. Bestard, A. (2019). La cortesía verbal santiaguera: imagen sociocultural de la ciudad. Revista Viña Joven, 21, (66), pp. 12-18. RNPS 0607. ISSN 2221-397X.

12. Bestard, A. (2019). Interacciones asimétricas en las conductas comunicativas de hablantes santiagueros. Opuntia Brava, (pp. 2714-2721). ISBN: 978-959-7225-34-8. 
13. Blanco B, I. (1980). El voseo en Cuba. Revista del Instituto Superior Pedagógico «Enrique J. Varona», 2, (4 y 5), 155-181.

14. Bravo, D. (2003). Actividades de cortesía, imagen social y contextos socioculturales: una introducción. En Actas del Primer Coloquio del Programa Edice «La perspectiva no etnocentrista de la cortesía: identidad sociocultural de las comunidades hispanohablantes». Recuperado de www.primercoloquio.edice.org.

12. Bravo D. \& Briz A. (2004) Pragmática sociocultural: estudios sobre el discurso de cortesía en español. Barcelona: Ariel.

13. Briz, A. (2004). Cortesía verbal codificada y cortesía verbal interpretada en la conversación. En Bravo, D. \& Briz, A. (Eds.), Pragmática sociocultural: estudios sobre el discurso de cortesía en español. Barcelona: Ariel.

14. Brown, R. \& Gilman A. (1960). The Pronouns of Power and Solidarity. Style on Language. Cambridge: Cambridge University Press.

15. Brown, P. \& Levinson S. (1987). Politeness. Cambridge: Cambridge University Press.

16. Callejas, D. (1983). Formas de tratamiento en el marco de la familia santiaguera en Santiago. Revista de la Universidad de Oriente, 51, 97-115.

17. Cathcart, M. (1981). La lengua: reflejo de la realidad histórico social. Revista Santiago, $42,120-130$.

18. Cathcart, M. \& Bonne, A. (1999). La realidad económica cubana y su reflejo en el léxico. El contacto lingüístico en el desarrollo de las lenguas occidentales. Quaderns de Filología. Estudios Linguistics. Universidad de Valencia.

19. Cathcart, M. \& Bonne, A. (2000). La relación lengua-cultura a través de un estudio sociolingüístico en comunidades. Revista Santiago, 89, En x Conferencia LingüísticoLiteraria, 8-12 de febrero. Santiago de Cuba.

20. Cordisco, Ariel (2003). Afiliación y desafiliación: contexto sociocultural en el análisis de la interrupción y de sus consecuencias sociales en la interacción. En Actas del Primer Coloquio del Programa Edice «La Perspectiva no Etnocentrista de la Cortesía: Identidad Sociocultural de las Comunidades Hispanohablantes». Recuperado de www.primercoloquio.edice.org.

21. Cuba, L. \& Hernández, J. (1996). La voz compañero en el español de Cuba. Revista Varona. La Habana.

22. Cuba, L. (2000). Formas nominales de tratamiento en el habla habanera actual. Revista Santiago, 89, En X Conferencia Lingüístico-Literaria, 8-12 de febrero. Santiago de Cuba. 
23. del Rosal, G. (2000). Funciones discursivas de las formas pronominales: posicionamiento del «yo» y del «otro» en el espacio apreciativo del tercero. Revista Santiago, En X Conferencia Lingüístico-Literaria, 8-12 de febrero, Santiago de Cuba.

24. Fetzer, A. (2011). Pragmatics as a Linguistic Concept. En W. Bublitz \& N. Norricck (Coords.), Foundations of Prgamatics (pp. 23-50). Berlin/New York. De Gruyter.

25. Koch, P. (2008). Tradiciones discursivas y cambio lingusístico: el ejemplo del tratamiento vuestra merced en español. En Katalek, J. (Coord.), Sintaxis histórica del español y cambio lingüístico: Nuevas perspectivas desde las tradiciones discursivas (pp. 5387). Frankfurt/Madrid: Vervuert.

26. Kerbrat-Orecchioni, C. (2004). ¿Es universal la cortesía? En Bravo, D. \& Briz, A. (Eds.), Pragmática sociocultural. Estudios sobre el discurso de cortesía en español (pp. 3953). Barcelona: Ariel.

27. López, H. (1994). Métodos de Investigación lingüística. Salamanca: Ediciones Colegio de España.

28. Martín, C., Perera, M. \& Díaz, M. (1996). La vida cotidiana en Cuba. Una mirada psicosocial. Revista Temas, 7, 23-32.

29. Molina, I (2002). Evolución de las formas de tratamiento en la juventud madrileña del siglo XIX: un estudio en tiempo real. Madrid: Gredos.

30. Moser, K. (2010). Las formas de tratamiento verbales-pronominales en Guatemala, El Salvador, Panamá y Costa Rica: hacia una nueva sistematización en la periferia centroamericana. En Hummel, M. M. et al. (Eds.), Formas y fórmulas de tratamiento en el mundo hispánico (pp. 271- 291). México: El Colegio de México/Karl-Franzens-Universität Graz.

31. Muñoz, A. (2005). Metalenguaje en el habla coloquial. En Actas del IX Simposio Internacional de Comunicación Social, 24-28 de enero. Santiago de Cuba.

32. Muñoz, D. (2005). Acerca de la modalidad del habla santiaguera. Viña Joven, 23. Centro Cultural Santa María Claret. Santiago de Cuba.

33. Murillo, J. (2003): La cortesía verbal en situaciones de habla en Costa Rica: hacia la comprensión de la imagen social en su contexto sociocultural. En Actas del Primer Coloquio del Programa Edice «La Perspectiva no Etnocentrista de la Cortesía: Identidad Sociocultural de las Comunidades Hispanohablantes». Recuperado de Www.primercoloquio.edice.org 
34. Murillo, J. (2005) Significados de la cortesía lingüística a partir de la aplicación de un test de hábitos sociales en Costa Rica. En. Murillo, J (Ed.), Actas del II Coloquio del Programa EDICE (pp.115-137). San José de Costa Rica: Universidad de Costa Rica.

35. Portolés, J. (2004) Pragmática para hispanistas. Madrid: Síntesis.

36. Rodríguez, G., Gil, J. \& García, E. (2002). Metodología de la investigación cualitativa. Santiago de Cuba: Prograf.

37. Real Academia Española (2000) Gramática descriptiva de la lengua española. Tomo I. Madrid: Espasa-Calpe.

38. Rebollo, L. (2006). Formas de tratamiento y cortesía en el mundo hispánico. Río de Janeiro: Universidad Federal de Río de Janeiro.

39. Reyes, T. (2005). El estudio del habla desde una perspectiva lingüístico-antropológica: casos en comunidades de Santiago de Cuba. En Actas del IX Simposio Internacional de Comunicación Social, 24-28 de enero. Santiago de Cuba.

40. Romaine, S. (1996). El lenguaje en la sociedad. Barcelona: Ariel.

41. Santiesteban, A. (1985). El habla popular cubana de hoy. La Habana: Editorial de Ciencias Sociales.

42. Schrott, A. (2017). Cortesía verbal y competencia lingüística: la petición cortés como tradición discursiva. Normas, 7 (1), 188-203.

43. Sielbold, K. (2008). Actos de habla y cortesía verbal en español y alemán. Estudios pragmalinguísticos e interculturales. Frankfurt: Peter Lang.

44. Schroder-Kniffki, M. (Coord.) (2016). La cortesía en el mundo hispánico. Nuevos contextos, nuevos enfoques metodológicos. Frankfurt: Vervuert. 